\title{
Breast Cancer: Reimbursement Policies and Adoption of New Therapeutic Agents by National Health Systems
}

\author{
Dario Trapani $^{\mathrm{a}}$ Giuseppe Curigliano $^{\mathrm{a}}$ Alexandru Eniu $^{\mathrm{b}}$ \\ ${ }^{a}$ Department of Oncology and Haematology, University of Milan, IEO, European Institute of Oncology IRCCS, Milan, \\ Italy; ${ }^{b}$ Department of Breast Tumours, Cancer Institute Ion Chiricuta, Cluj-Napoca, Romania
}

\begin{abstract}
Keywords
Reimbursement · Cancer medicines · Innovation ·

Breast cancer · Priority setting
\end{abstract}

\begin{abstract}
Background: Breast cancer is a cause of morbidity for more than half a million of patients in Europe, resulting in broad societal impacts that affect patients, families, and societies from a human, emotional, economic, and financial perspective. Expenditure for cancer medicines represents one of the principal driving costs of healthcare. The aim of this review is to describe the European policy and regulatory landscape of innovation uptake in breast oncology - with emphasis on value in cancer healthcare. Summary: In Europe, several reimbursement models or policy tools have been developed by countries to compose their benefit packages. The most commonly applied scheme is the product-specific eligibility model, prioritizing selected medicines and their indications. Mixed models are commonly developed, addressing the protection of more vulnerable people, ensuring protection from impoverishment caused by cancer and containing disparities. However, the risk to incur significant out-of-pocket expenses for essential or newer medicines for cancer is still substantial in Europe, especially in low- and middle-income countries, determining greater financial distress and poorer outcome for patients. Value-based priority setting is an essential mechanism to ensure timely access to the most valuable medicines for breast cancer patients. Estimations of the value of medicines can be provided within health technology assessment services and networks and informed by benefit scales and tools. Key Messages: There is ample room for
\end{abstract}

\section{KARGER}

๑) 2019 S. Karger AG, Basel reciprocal support across the diverse cultural and legal realities in Europe. The aim is common: save cancer patients from premature death by ensuring the timely access to the best care, protecting from financial hardships and distress to leave no cancer patient behind in poverty. Steps are to be taken to promote value-based priority setting, paving the way toward universal health coverage in Europe, where health of people is protected, and affordable best quality care is the only standard pursued and acceptable.

(c) 2019 S. Karger AG, Basel

\section{Introduction: The Financial Burden of Cancer in Europe, a Heterogeneous Environment within a Multitude of Diverse Countries}

Cancer is a major health challenge, reported as the second cause of mortality worldwide and a principal cause of morbidity, disability, and premature death. Cancer caused 9.6 million deaths in 2018, affecting $>18$ million people in the world: it has broad societal impacts that affect patients, families, and societies from a human, emotional, economic, and financial perspective [1].

Expenditure for cancer medicines represents one of the overall driving costs of healthcare in Europe. The trend of expenditure for cancer medicines is rapidly rising at a higher rate than the overall healthcare expenditure, primarily as a consequence of approval and reimbursement of novel high-cost drugs [2]. Great variability exists across the European countries regarding the reimbursed medicines. A wide array of social and economic determinants, as well as the financing arrangements and 
organizational structure of the health systems and their performance are influencing the health expenditure [3]. For instance, the 2017 report of the Organisation for Economic Co-operation and Development (OECD) revealed a difference in healthcare expenditure that can be as high as 4 times more in some high-income countries, like Luxembourg, Germany and Sweden compared to certain Eastern Europe countries, like Poland, Bulgaria, and Romania (i.e., EUR 4,000 in comparison to EUR 1,000 per person, yearly). Health expenditure represented on average $<10 \%$ of the European gross domestic product or GDP (range $4.2-12.3 \%$ ). Interestingly, $20 \%$ of the allocated resources were spent on medical goods (mainly pharmaceuticals), ranging between EUR 203 and 742 pro capita. Nevertheless, patterns of expenditure for medicines varied across countries: in some countries, the outof-pocket expenditure for medicines accounted for more than two-thirds of the total expenditure, while in other, social protection offered up to $80 \%$ of reimbursement within a governmental insurance scheme.

Direct health costs of cancer care expenditure were estimated at around EUR 86 billion (in 2014), of which $22 \%$ was attributable to cancer medicines [4]. Across the countries, the expenditure pro capita for cancer ranged between EUR 55 and 323 per inhabitant. However, the direct financial burden of cancer for the patients is still significant - even in higher-income European countries consistently spending on cancer healthcare. In one study from Germany, for example, more than one-third of cancer patients reported income loss as a sequel to their disease, impacting on patient's quality of life and producing distress [5]. One survey from France revealed that breast cancer patients are exposed to a higher risk of financial distress from the out-of-pocket expenses, impairing their quality of life [6].

\section{The Financial Burden of Breast Cancer Care}

Due to its epidemiological burden and wide options of effective multimodal treatments, breast cancer is generally related to significant financial efforts for health systems. In Europe, more than half a million of women and men have been diagnosed with breast cancer in 2018, accounting for 137,000 deaths [1]. In Europe, breast cancer has the highest healthcare costs, accounting for $12 \%$ of the total cancer healthcare costs in the region [7]. Direct and indirect economic costs attributable to breast cancer are substantial, and cost burden increases with disease stage. It is estimated that the mean treatment costs of stages II, III, and IV breast cancer are 32, 95, and 109\% higher than those of stage I disease, and the mean treatment costs of regional and distant breast cancer are 41 and $165 \%$ higher than those of local disease [8]. In patients with later stages of disease, higher total cost burden is generally experienced by patients, an estimated USD
47,000-67,000 per person in one revision of the literature (which applies more to high-income countries) [9].

Since 2000, when the first targeted therapy for breast cancer has been approved, several novel targeted agents for breast cancer have been approved and reimbursed, providing more opportunities for patients to be cured and survive longer, leading to an important increase in the financial burden. In one high-income European study issued by an insurance company, the costs of treating breast cancer patients increased overall since 2006; the main determinants for costs increase were medicines, in particular targeted agents, while only a slight increase was evident for hormone and cytotoxic agents [10].

This situation underlines that the containment and rationalization of spending for healthcare is critical at all levels and needs a multisectoral management that considers selection and prioritization of the medicines per effectiveness and quality, informing the patterns of reimbursements and resulting in no risk for patients to incur in poverty because of cancer. Out-of-pocket expenses, in fact, and in general financial distress including catastrophic health expenditure related to treatment lead to decreased quality of life and impede the delivery of the highest-quality-standard treatments, substantially affecting the cancer outcome of patients [11].

Financial burden of cancer is actually a major and often neglected determinant of the outcome of cancer patients [12].

\section{An Overview of the Reimbursement Policies and Tools for Decision-Making in Europe}

\section{The Reimbursement Models}

A multitude of reimbursement schemes and models have been developed in Europe, as a single model is not applicable in all contexts. Commonly, $>1$ model is used in one country; however, a dominant scheme can often be recognized within a mixed approach.

Reimbursement models can be based on eligibility criteria for defining coverage according to diseases or populations, specific medicines or class of medicines and consumption, or income. Tools and strategies used to aid the process are positive and negative reimbursement lists, managed entry agreements (MEA), and reference pricing lists [13].

Product-specific schemes are based on the selection of specific medicines for partial (co-payment) or full reimbursement (no co-payment); medicines outside the scheme are labelled as non-reimbursable and are provided only as out of pocket. The decision to reimburse can be informed by several criteria, often $>1$. Usually, reimbursement bodies take into consideration several aspects including cost-effectiveness, medical unmet need, public 
health relevance, and the value or magnitude of benefit of medicines.

A disease-specific scheme reimburses medicines and treatment protocols for specific disease or health conditions. This means that the emphasis is put on the value of the medicines in the context of the disease, so that the same medicines can be differently reimbursed, according to the role in disease management.

A population group-specific reimbursement addresses single disease, age-restricted groups or populations exposed to impoverishment, and social and financial vulnerability.

Some models for reimbursement are based on more stringent supply-demand cogency within a defined timeline, like the consumption-based eligibility schemes. In such models, patient's gross pharmaceutical expenditure is limited up to a threshold of out-of-pocket expenses, that can be fix or variable across different populations and period of the year; when the patient surpasses the threshold, a partial or total reimbursement scheme applies.

In addition to the lists, the reference pricing system is based on a common reimbursement level or reference price for a group of interchangeable medicines (reference group) [14]. Beyond stimulating more convenient price negotiations and enhance resource- saving, reference pricing system can increase the selection from patients of generics, sparing some of the direct out-of-pocket costs of illness. It can potentially synergize with the obligations for generic substitution and in some instance, for biosimilars.

MEA are another strategy that is aimed at providing risk sharing among payers and pharma industry. MEA are real contracts between the public payer and the companies, aiming to mitigate the uncertainties of effectiveness, especially for drugs coming from adaptive pathways (introduction of a promising pharmaceutical product earlier along the product life cycle like conditional marketing authorizations) [15]. The risk sharing aims to minimize the costs for the health system as not all patients benefit from a certain medication; it is based on criteria for the validation of the benefit achieved, including performance- and value-based MEA, when clinical outcomes are taken into account (efficacy, effectiveness, toxicity, medical unmet need).

\section{The Policy Tools in Assistance of the Reimbursement} Models

Lists of reimbursements are compiled in the development of benefit packages of medicines, namely the medicines selected for the partial or total reimbursement (positive lists, formulary) for defined clinical indications. In general, countries list and update more commonly the medicines to reimburse and not the ones not eligible to reimbursements (negative list) [13]. However, explicit
Table 1. Criteria for reimbursement of medicines utilized in European countries to inform priority setting in the construction of benefit packages

\begin{tabular}{|c|c|c|c|c|c|}
\hline Country & $\begin{array}{l}\text { Added } \\
\text { value }\end{array}$ & $\begin{array}{l}\text { Medical } \\
\text { priority }\end{array}$ & Safety & $\begin{array}{l}\text { Cost- } \\
\text { effectiveness }\end{array}$ & $\begin{array}{l}\text { Budget } \\
\text { impact }\end{array}$ \\
\hline Armenia & $\checkmark$ & $\checkmark$ & $\checkmark$ & & \\
\hline Austria & $\checkmark$ & & & & \\
\hline Belarus & & & & $\checkmark$ & \\
\hline Belgium & $\checkmark$ & & & & $\checkmark$ \\
\hline Bulgaria & $\checkmark$ & & $\checkmark$ & & $\checkmark$ \\
\hline Croatia & $\checkmark$ & & & & \\
\hline Czech Republic & $\checkmark$ & & & $\checkmark$ & $\checkmark$ \\
\hline Denmark & $\checkmark$ & & $\checkmark$ & & \\
\hline Estonia & $\checkmark$ & $\checkmark$ & $\checkmark$ & $\checkmark$ & $\checkmark$ \\
\hline Finland & $\checkmark$ & $\checkmark$ & & $\checkmark$ & $\checkmark$ \\
\hline Iceland & & & $\checkmark$ & & $\checkmark$ \\
\hline Kazakhstan & $\checkmark$ & $\checkmark$ & & $\checkmark$ & \\
\hline Latvia & $\checkmark$ & & & $\checkmark$ & $\checkmark$ \\
\hline Lithuania & $\checkmark$ & & & $\checkmark$ & $\checkmark$ \\
\hline Malta & $\checkmark$ & & $\checkmark$ & $\checkmark$ & \\
\hline Netherlands & $\checkmark$ & $\checkmark$ & $\checkmark$ & $\checkmark$ & \\
\hline Norway & & $\checkmark$ & & $\checkmark$ & $\checkmark$ \\
\hline Poland & $\checkmark$ & $\checkmark$ & $\checkmark$ & $\checkmark$ & $\checkmark$ \\
\hline Portugal & $\checkmark$ & & & & \\
\hline Moldova & $\checkmark$ & $\checkmark$ & $\checkmark$ & & $\checkmark$ \\
\hline Russia & & & $\checkmark$ & & \\
\hline Serbia & $\checkmark$ & & & & \\
\hline Slovenia & $\checkmark$ & & & & $\checkmark$ \\
\hline Spain & $\checkmark$ & & & & \\
\hline Turkey & & $\checkmark$ & & $\checkmark$ & $\checkmark$ \\
\hline Ukraine & $\checkmark$ & $\checkmark$ & & & \\
\hline UK & & & & $\checkmark$ & \\
\hline
\end{tabular}

Source: WHO Europe [16].

negative lists may enhance the de-investments process, when lower-value interventions have been previously initiated or inaccurately developed and require de-engagement for priority investments.

\section{A Situational Analysis in Europe}

Several reimbursement models or policy tools are generally used by each country to compose their benefit packages. The most commonly applied scheme is the productspecific eligibility model, present in nearly three-quarter of European countries (32 out of 45), according to World Health Organization (WHO) European Regional Office (EURO) report entitled "Medicines Reimbursement Policies in Europe" [16]. However, hybrid systems are also used, including a group-specific model with a supplementary product-specific scheme in Ireland and a disease-specific scheme in Kazakhstan. An approach exclusively per disease types in the outpatient setting is predominant in the Baltic countries as well as in the Commonwealth of Independent States of the former Soviet Union. However, as the value of medicines can vary across different clinical 


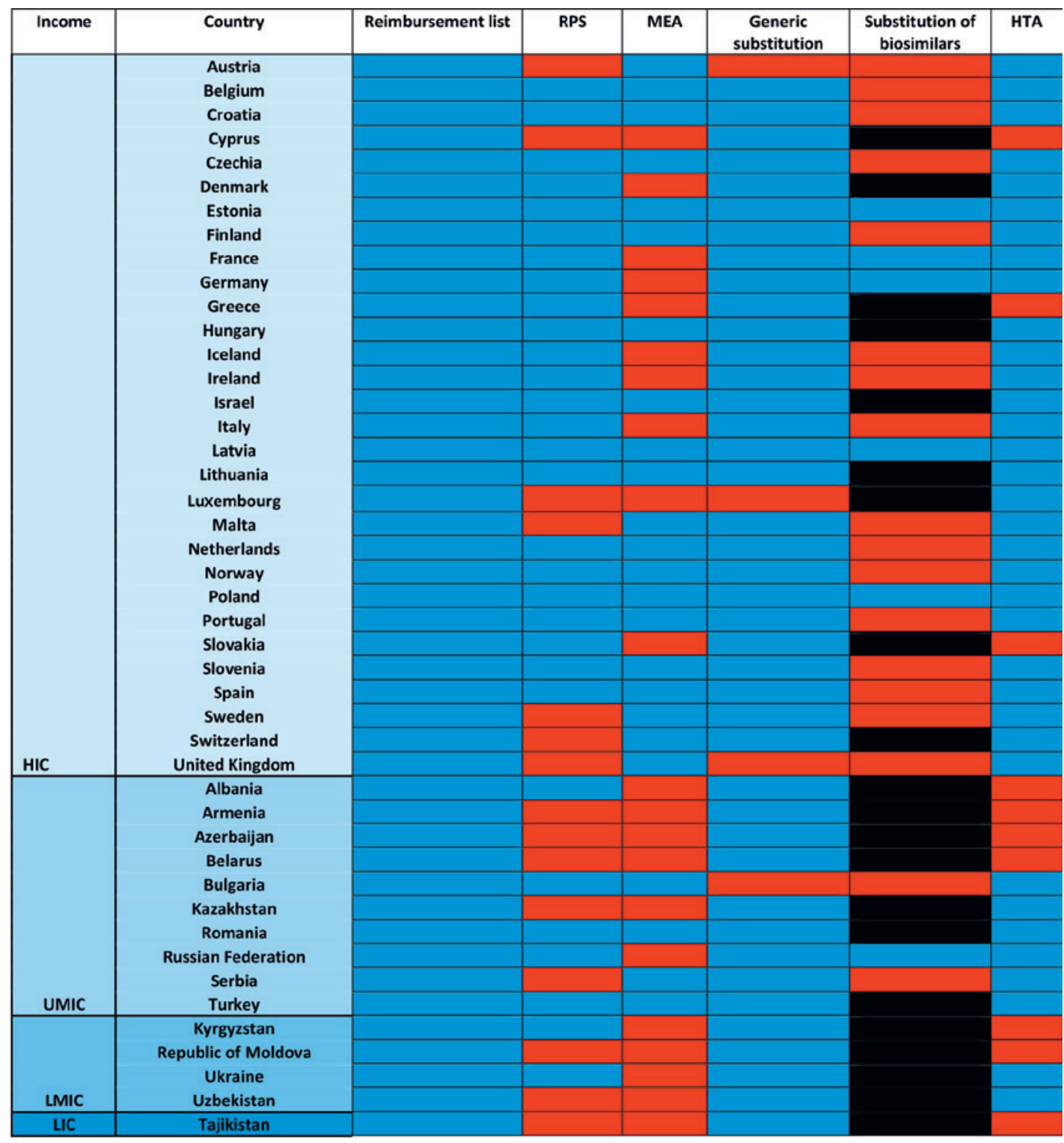

Yes

No

Not available

Fig. 1. An overview of the normative environment for reimbursement of medicines in Europe [16]. For generic substitution, "yes/ no" are intended as "allowed/not allowed"; for HTA, "no" includes the countries that were developing an HTA service at the time of the survey, not yet operational. Reimbursement lists include posi-

indications, a supplementary disease-specific scheme can be present under a product-specific model, as is the case in France, Ireland, and Portugal; this approach allows a refinement in the reimbursement of the medicines for diseases, providing a framework close to an evidence-informed and perhaps value-based priority setting.

Population group-specific reimbursements usually use a modular system that can allow to differentiate ac- tive and negative lists. HIC, high-income country; UMIC, uppermiddle-income country; LMIC, lower-middle-income country; LIC, low-income country; RPS, reference price system/internal reference pricing; MEA, managed entry agreements for medicines in the outpatient setting; HTA, health technology assessment. cess, according to income and productivity. In Turkey, the co-payment is set at $20 \%$ for workers, while retired people have a co-payment of $<10 \%$.

The major factors included in the decision-making for reimbursement in Europe include added value to existing therapies, medical priority and unmet needs, safety, costeffectiveness, and budgetary impact (Table 1). In Europe, only 2 countries include all these features in the decision for 


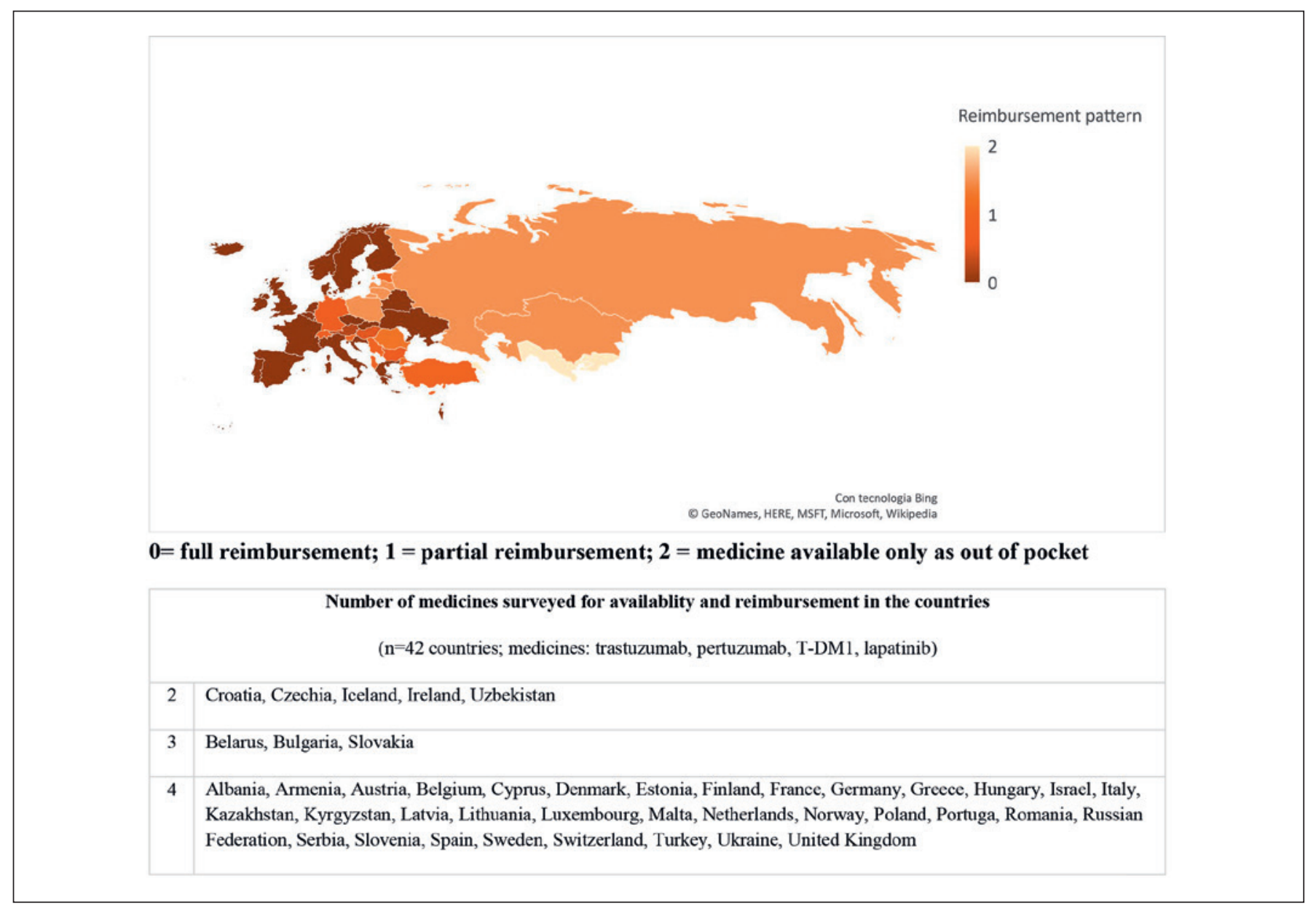

Fig. 2. Pattern of reimbursement of cancer medicines according to the 2016 ESMO survey in European Countries on cancer medicines availability and affordability [20]. The map reports an averaged estimation for the 4 medicines surveyed and must be intended as indicative.

reimbursement (Estonia, Poland); overall, countries consider 2.5 features, on average. Eight countries were able to make decision based on a single element, that was mainly the added value to preexisting therapies: this was the most commonly considered decisional factor across the countries. However, chronic diseases are usually given priority, and commonly these patients have no extra co-payments. The identification of the vulnerable populations in this model could be the path to catalyze Universal Health Coverage, for the poor, underserved, and frailest populations. In general, cancer qualifies as a chronic disease to reduce the out-of-pocket expenses and financial burden for the patient, as reported for Albania, Finland, Romania, and the UK. A mixed scheme also applies to chronically ill patients under a scheme per population group, to offer the most convenient solutions to accommodate people's needs.

Policy Tools to Inform and Operationalize the

Reimbursement Models in Europe

All the countries surveyed in the WHO EURO report acknowledged the usefulness of a reimbursement list to facilitate and operationalize the medicines strategies [16] (Fig. 1). However, only 3 countries (Spain, UK, Germany) compiled a negative list, to stress the medicines not eligible to reimbursement, as a result of a technical and policy assessment. Interestingly, Germany emphasized the importance of de-investments or non-priority investments by compiling only a negative list, in countertendency to the other European countries. When grouping the countries per income, differences in the capacity to build and operationalize policy-making processes is evident. In European lower- and middle-income countries, $>60 \%(n=8 / 13)$ were not considering a reference pricing list and $85 \%(n=11 / 13)$ had no potential for value-based negotiations of cancer medicines via MEA.

Generic substitution was generally allowed and mandatory in one-quarter of the countries $(n=12 / 45)$. Only 4 countries did not allow generic substitution, and none were low- or lower-middle income countries. There was wide variability in the patterns of substitution of biosimilars; for instance, one survey in Central and Eastern Europe revealed that substitution and interchangeability 
were generally allowed, although in most countries the decision was left at the discretion of the physician after a clinical judgment [17]. Some countries in Europe apply restriction to the use and reimbursement of biosimilars, limiting it to the indications assessed in the non-inferiority exercise (no extrapolation allowed in Croatia and Serbia), only in non-first-line therapies, or for selected extrapolated indications (Malta, Bulgaria) [18]. This partially contrasts with the international positions and evidence on the topic, especially for the cases when substitution is allowed [19].

\section{Reimbursement Pattern of Selected Breast Cancer Medicines in Europe and the Consequences of Policy Decisions}

The state of the reimbursement of cancer medicines in Europe has been evaluated in 2016 through a survey of the European Society for Medical Oncology (ESMO) on their accessibility and availability [20] (Fig. 2). The study revealed substantial differences in the formulary availability, out-of-pocket costs and affordability of several anticancer medicines, including WHO essential medicines [21]. For cytotoxic chemotherapy indicated in breast cancer, the majority of European Countries provided the full reimbursement or with a minimal quota of co-payments. Non-priority breast cancer medicines providing a narrower magnitude of benefit were more commonly reimbursed in Western European countries and not prioritized in the benefit packages of most Eastern European countries. However, some challenges were revealed for more expensive or innovative drugs with a valuable role in breast cancer treatment, including trastuzumab. Of note, trastuzumab is a WHO essential medicine for breast cancer [21]. The analysis of 42 countries (12 lower- and middle-income) of WHO European Region revealed that high-income countries were more likely able to provide the anti-human epidermal growth factor receptor 2 (HER2) medicines with a full reimbursement or low co-payments than low- and middle-income countries. One out of 4 lower- and middle-income countries provided no reimbursement for trastuzumab, resulting in significant out-of-pocket expenses; the rates increased to 3 out of 4 , when pertuzumab and T-DM1 were analyzed. In high-income countries, no co-payment was requested for trastuzumab and less than one-quarter required co-payments for the other newer anti-HER2 compounds.

Overall, the data provide a direct link between policy decisions to reimburse/not reimburse medicines and patients' access to valuable medicines. For instance, trastuzumab is an essential medicine for the treatment of breast cancer overexpressing HER2, with a recognized potential to save more lives [22]. Pertuzumab and T-DM1 are not considered essential medicines but can have a role in the management of patients in resource-enhanced settings, namely in a setting where essential medicines can be assured to all cancer patients and preventive, early detection, and curative treatments have already been developed; in fact, both these medicines scored well using the ESMO Magnitude of Clinical Benefit Scale (MCBS), a policy tool developed to inform on the intrinsic value of cancer medicines; a score of 4 out of 5 stated their relevance in cancer treatment, provided they are affordable [23]. Evidence-based policy and policy-making tools like MCBS have the potential to select and prioritize relevant cancer interventions by effectiveness and cost-effectiveness, to assure maximal benefit for most patients. Indeed, it addresses the delicate question of equity in care, to ensure no cancer patient is discriminated, regardless of the diagnosis she/he carries, histology, subtype, or stage at presentation. This requires planning cancer programs within resilient health systems and implementing care across the entire cancer continuum.

The link between cancer planning and cancer outcome has been clarified more recently and modelled on breast cancer. A study from the OECD assessing the performance of health systems in Europe quantified the prognostic role of national cancer planning, namely how policy-making impacts on patients' outcome [24]. The study revealed that expenditure on cancer medicines, access to innovative medicines, and GDP were correlated with outcome. The analysis showed that several elements correlated with the survival for breast cancer patients: an implemented national cancer control plan developed according to cancer-specific targets within defined timeframes, monitored and with quality assurance and standard protocols of treatment. The quality of governance in policy-formulating was the key determinant for outcome, together with budget size and resource allocation, prioritization, and quality - all elements of performance of the health systems.

One of the parameters to evaluate the health system performance for cancer is the mortality-to-incidence ratio (MIR); however, it is also clear that the MIR is not a good proxy for cancer-specific survival and must not be used for the estimations of cancer burden in populations $[25,26]$. One study from Central and Eastern Europe found that the average expenditure on oncology drugs per capita was 2.5 times higher in Western than Eastern Europe [27]. A negative correlation was described between the expenditure for oncology medicines and the MIR, suggesting that appropriate investments indicate a better performance of healthcare systems for cancer, potentially resulting in a better outcome for patients. Accordingly, a value- based prioritization in medicines was suggested to reduce the disparities in cancer treatments 
across European countries, blending clinical care and policy-making.

So, what is Europe doing to mitigate the disparities of outcome of cancer patients, when policy recommendations or limited budget exposes patients to inequalities in access to treatment? Long-term sustainable solutions based on the country need are highly desirable, especially when timely developed. To mitigate some inequalities in access to healthcare expertise that can be only found in reference centers, a cross-border healthcare policy has been structured, under the European Union Directive 2011/24 [28]. The Directive aims to enhance the access to treatments, with emphasis on rare disease, including enetworking of experts.

\section{The Role of Health Technology Assessment in the Uptake of Innovation and Adoption of New Therapeutic Agents}

Health technology assessment (HTA) is a multisectoral and multi-expertise approach to the evaluation of medicines and medical devices and goods based on a multidisciplinary approach that embraces all the relevant knowledge for health - effectiveness, health economics, social science, and medical humanities [29]. An HTA approach for the selection and prioritization of medicines has been suggested by the WHO [30]. In Europe, the European Union has been working on HTA since 2008, especially to inform the decisions on medicines to be financed and reimbursed, supporting the price negotiation process [31]. The European network for health technology assessment (EUnetHTA) is a multiple stakeholder coordination mechanism created "to define and implement a sustainable model for the scientific and technical cooperation on HTA", on a voluntary basis [32]. The network includes patients, consumers, health providers, payers and industry Stakeholders. The aim of the network is to strengthen international collaboration to reduce duplications of efforts and support countries with lower capacities to set up and sustain an HTA service. This can be critical when HTA are developed with substandard capacities or supported by unilateral stakeholders, with the risk to provide non-evidence-based or biased policy information, for example, due to lack of multisectoral engagement or poor involvement of civil society [33]. Notably, nearly $50 \%$ of low- and middle-income European countries do not rely on an HTA approach to inform the policy of reimbursement of medicines due to low capacity to develop and sustain the assessment mechanism (Fig. 1). HTA provides the tools for evaluation and priority setting of innovative therapies. In the context of valuebased prioritization and sustainability of resilient health systems, the HTA model has been complemented broad- ly by the development of frameworks and tools, to address the selection and pricing of medicines via a multidimensional approach. The WHO essential medicine list (EML) cancer medicines working group stated that the HTA-based prioritization process for selection of medicines can be informed by scales of value, developed as policy-assisting tools across the continuum of healthcare, rooting in the clinical expertise and close to the patients' voices. Inter alia, the ESMO MCBS has been recognized as a reliable scale to screen valuable medicines for consideration in the EML, serving oncology across the globe [23]. In one validation study of MCBS against the regulatory environment in Israel, the scale showed good correlation with the HTA-based decision-making of the country, suggesting that the use of the scale could complement and integrate the HTA process for medicines. The MCBS scale can provide a rapid assessment/screening tool for countries with low HTA capacity and not (yet) included in the HTA cross-country networks [34]. Overall, the use of MCBS and of the value frameworks has been proposed to integrate the HTA process, welcoming a "structured and systematic approach that can discriminate between oncology medicines of higher value than others for assisting in the rational and appropriate use of limited public resources to deliver effective and affordable care" [35].

For breast cancer, the use of WHO EML and the information from MCBS could be a powerful strategy to prioritize the most effective medicines with an impact on healthcare, ensuring value for money (see suppl. Appendix 3; see www.karger.com/doi/10.1159/000502637 for all suppl. material). In particular, the MCBS-informed HTA approach can serve as the effective environment to enhance the timely uptake of novel medicines, screening among a plethora of new drugs and technologies - including diagnostic tools and companion diagnostics.

\section{Off-Patent Medicines: Optimization of Policies for}

Uptaking of Generics and Biosimilars in Europe

The implementation of national medicines policies has been regarded by European countries as the bedrock to guide actions toward national and regional health systemrelated goals. The principle is more commonly embedded in the national allocation of the resources, ensuring no diversion from essential health products and service by favoring substandard or less relevant interventions [2]. According to the WHO, health-related goals have the cogent aim to ensure timely and equitable patient access to effective and affordable medicines with established safety, efficacy, and quality via multiple policies, including the ones devoted to cost containment and rationalization. Explicit economic goals are also acknowledged: the improvement of prescribing and dispensing medicines is part of them. In the era of value-based healthcare, the substitution of quality generic and approved biosimilars for off-patent drugs 
is the key to assure sustainable development of cancer healthcare, particularly for the control of the costs of healthcare. The uptake of generics and substitution with branded molecules is a current common practice in $\mathrm{Eu}-$ rope; however, disparities exist as every country has interpreted the value of the exercise of biosimilarity differently, shaping often restrictive normative environments [16]. One study performed in Eastern European countries revealed that prices of biosimilars range between 25 and 55\% of the price of the originator [17]. One country (Romania) adopted in 2014 an HTA approach for reimbursement of biosimilars, based on number of European countries with a positive reimbursement status and therapy cost. However, according to the more recent positions of the scientific and medical societies, the uptake of biosimilars must be endorsed and facilitated to assure the equal and timely access to affordable medicines, reducing the overall direct costs of illness; this means that a new HTA evaluation in all the single countries could be spared, favoring the benefit of the timely and earlier uptake of biosimilars, as well established for generics. Introduction of biosimilars across several indications is expected to have cumulative potential savings of EUR 50-100 billion by 2020 [36].

In this regard, the statement on biosimilars from ESMO is clear: efforts must be provided to address the timely access to innovation, especially cancer medicines, and be sure that less effective non-priority medicines are identified, informing the policy-makers. It is also clear that "with potential savings and rapidly increasing range of biologic products and well-informed healthcare professionals and patients, biosimilars do represent one of the ways forward to obtain sustainability" [19]. Major national efforts to re-estimate again and again the quality of approved biosimilars is discouraged, when the exercise of biosimilarity has been fulfilled based on a rigorous quality methodology and satisfying the regulatory requirements; facilitations to catalyze access to valuable medicines at a lower cost is primarily a commitment for patients and healthcare self-preservation and development.

\section{Conclusions}

Reimbursement policies and strategies to enhance access to innovative therapies for breast cancer are heterogeneous across Europe. Under the normative environment and leadership of the EU and with the support of key international Societies, projects to facilitate the formulation of effective policies for cancer medicines are underway. Access to quality valuable medicines, primarily essential medicines and priority medicines has demonstrated to translate into a better outcome for patients. However, the variability in the organization and resilience of health systems in ef- fectively responding to the rapid development of oncology knowledge along with the burden of uptake of new medicines has represented a major challenge for many countries, particularly when decisions on reimbursement must be taken. Despite diverse normative environments, collaboration is endorsed by European countries by working together for cross-border agreements in the area of healthcare as well as sharing experience and expertise, building up successful frameworks to inform national policy-making and HTA networks. The lesson of European countries is that across diverse cultural and legal realities, including income, there is ample room for reciprocal support, acknowledging the ultimate goal of health system strengthening: save patients from premature death by ensuring the timely access to the best care, protecting from financial hardships and distress to leave no cancer patient behind in poverty. Steps are to be taken to promote value-based priority setting in order to pave the way toward universal health coverage, where health of people is protected, and best quality care is the only standard acceptable.

\section{Disclosure Statement}

G.C. received personal fees from Seattle Genetics, Pfizer, Lilly, Novartis, Roche, and Ellipsis for consultation. A.E. and D.T. declare no competing conflict of interest.

\section{Funding Sources}

No financial support was provided for this work.

\section{Author Contributions}

All the authors contributed equally to the development of the paper. A.E. led the work, providing coordination of the authors. A.E. and D.T. suggested the primary outline. D.T. gathered the data from different sources. G.C. contributed with meaningful insights about breast cancer care and relative policies in Europe. All the authors contributed to the writing; they all read and approved the final draft.

\section{References}

1 IARC. Global Cancer Observatory. Available from: https://gco.iarc.fr (last accessed 13 November 2018).

2 WHO. Pricing of cancer medicines and its impacts (2018). Available from: https://apps. who.int/iris/bitstream/handle/10665/ 277190/9789241515115-eng.pdf?sequence= 1\&isAllowed $=y$ (last accessed 7 July 2019).

3 OECD. Health at a Glance: Europe 2018. STATE OF HEALTH IN THE EU CYCLE (2018). Available from: https://ec.europa.eu/ health/sites/health/files/state/docs/2018 healthatglance_rep_en.pdf (last accessed $\overline{7}$ July 2019). 
4 Wilking NE, Hofmarcher T, Lindgren $\mathrm{P}$, Jönsson B. The burden and direct cost of cancer in Europe (EU-28). J Clin Oncol. 2016 May;34(15 suppl):6618-6618.

5 Winkler EC, Mehlis K, Surmann B, Witte J, Lingnau R, Apostolidis L, et al. Financial toxicity in German cancer patients. How does a chronic disease impact the economic situation? Ann Oncol. 2018 Oct;29(8 suppl): 1576P_PR.

6 Barbaret C, Brosse C, Rhondali W, Ruer M, Monsarrat L, Michaud P, et al. Financial distress in patients with advanced cancer. PLoS One. 2017 May; 12(5):e0176470.

7 Luengo-Fernandez R, Leal J, Gray A, Sullivan R. Economic burden of cancer across the European Union: a population-based cost analysis [Internet]. Lancet Oncol. 2013 Nov; 14(12): 1165-74. [cited 2019 Jul 7].

8 Sun L, Legood R, Dos-Santos-Silva I, Gaiha SM, Sadique Z. Global treatment costs of breast cancer by stage: A systematic review [Internet]. PLoS One. 2018 Nov; 13(11): e0207993. [cited 2019 Jul 7].

9 Masaquel C, Jerusalem G, Copley-Merriman K, Ray D, Higuchi K, Caceres V. Economic Burden of Advanced Breast Cancer. Value Heal. 2016 May;19(3):A146.

10 Helsana $(\mathrm{CH})$. Treatment Costs by Agents within Helsana. 2014. Available from: https:// www.helsana.ch/docs/breast-cancer.pdf (last Access 25 June 2019).

11 Zafar SY, Abernethy AP. Financial toxicity, Part I: a new name for a growing problem [Internet]. Oncology (Williston Park). 2013 Feb; 27(2):80-1. [cited 2019 Jul 7] Available from: https://www.ncbi.nlm.nih.gov/pmc/articles/ PMC4523887/.

12 Tran G, Zafar SY. Financial toxicity and implications for cancer care in the era of molecular and immune therapies. Ann Transl Med. 2018 May;6(9):166.

13 OECD. (2007). Pharmaceutical pricing and reimbursement policies in Switzerland. Available from: https://www.oecd.org/switzerland/38868953.pdf (last Access 25 June 2019).

14 Dylst P. Reference pricing systems in Europe: characteristics and consequences. Generics Biosimilars Initiative J. 2012 Aug;1(3-4):12731.

15 Bouvy JC, Sapede C, Garner S. Managed Entry Agreements for Pharmaceuticals in the Context of Adaptive Pathways in Europe [Internet]. Front Pharmacol. 2018 Mar;9:280. [cited 2019 Jul 7].
16 WHO EURO. Medicines reimbursement policies in Europe (2018). Available from: http:// www.euro.who.int/__data/assets/pdf_ file/0011/376625/pharmaceutical-reimbursement-eng.pdf?ua=1 (last Access: 26 June 2019).

17 Kawalec P, Stawowczyk E, Tesar T, Skoupa J, Turcu-Stiolica A, Dimitrova M, et al. Pricing and Reimbursement of Biosimilars in Central and Eastern European Countries [Internet]. Front Pharmacol. 2017 Jun;8:288. [cited 2019 Jul 7].

18 Moorkens E, Vulto AG, Huys I, Dylst P, Godman B, Keuerleber S, et al. Policies for biosimilar uptake in Europe: an overview [Internet]. PLoS One. 2017 Dec;12(12):e0190147. [cited 2019 Jul 7].

19 Tabernero J, Vyas M, Giuliani R, Arnold D, Cardoso F, Casali PG, et al. Biosimilars: a position paper of the European Society for Medical Oncology, with particular reference to oncology prescribers [Internet]. ESMO Open. 2017 Jan;1(6):e000142. [cited 2019 Jul 7].

20 Cherny N, Sullivan R, Torode J, Saar M, Eniu A. ESMO European Consortium Study on the availability, out-of-pocket costs and accessibility of antineoplastic medicines in Europe. Ann Oncol. 2016 Aug;27(8):1423-43.

21 WHO. WHO Model List of Essential Medicines (2017). Available from: https://apps.who.int/ iris/bitstream/handle/10665/273826/EML-20eng.pdf (last access 7 July 2019).

22 Curigliano G, Burstein HJ, Winer EP, Gnant M, Dubsky P, Loibl S, et al.; St. Gallen International Expert Consensus on the Primary Therapy of Early Breast Cancer 2017. De-escalating and escalating treatments for earlystage breast cancer: the St. Gallen International Expert Consensus Conference on the Primary Therapy of Early Breast Cancer 2017. Ann Oncol. 2017 Aug;28(8):1700-12.

23 Cherny NI, Dafni U, Bogaerts J, Latino NJ, Pentheroudakis G, Douillard JY, et al. ESMOMagnitude of Clinical Benefit Scale version 1.1 [Internet]. Ann Oncol. 2017 Oct;28(10): 2340-66. [cited 2018 Aug 26].

24 OECD. Cancer Care: Assuring quality to improve survival (2013). Available from: http:// www.oecd.org/ (last Access: 26 June 2019).

25 Choi E, Lee S, Nhung BC, Suh M, Park B, Jun $\mathrm{JK}$, et al. Cancer mortality-to-incidence ratio as an indicator of cancer management outcomes in Organization for Economic Cooperation and Development countries [Internet]. EpidemiolHealth.2017 Feb;39:e2017006.
26 Ellis L, Belot A, Rachet B, Coleman MP. The Mortality-to-Incidence Ratio Is Not a Valid Proxy for Cancer Survival [Internet]. J Glob Oncol. 2019 May;5(5):1-9. [cited 2019 Jul 7].

27 Vrdoljak E, Bodoky G, Jassem J, Popescu R, Pirker R, Čufer T, et al. Expenditures on Oncology Drugs and Cancer Mortality-to-Incidence Ratio in Central and Eastern Europe. Oncologist. 2019 Jan;24(1):e30-7.

28 European Parliament. Directive 2011/24/EU of the European Parliament and of the Council of 9 March 2011 on the application of patients' rights in cross-border healthcare (2011). Available from: https://eur-lex.europa.eu/legal-content/EN/TXT/?uri=CELEX\%3A320.

29 WHO. Health technology assessment (2019). Available from: https://www.who.int/medical_devices/assessment/en/ (last access 7 July 2019).

30 WHO. Sixty-seventh world health assembly. WHA67 Resolutions (2014). Available from: http://apps.who.int/gb/ebwha/pdf_files/ WHA67-REC1/A67_2014_REC1-en.pdf (last access 7 July 2019).

31 EMA. Health technology assessment bodies (2019). Available from: https://www.ema.europa.eu/en/partners-networks/health-technology-assessment-bodies (Last access 7 July 2019).

32 EUnetHTA. Available from: https://www.eunethta.eu/ (last access 7 July 2019).

33 Reuzel RP, van der Wilt GJ, ten Have HA, de Vries Robbé PF. Reducing normative bias in health technology assessment: Interactive evaluation and casuistry. Med Heal Care Philos. 1999;2(3):255-63.

34 Hammerman A, Greenberg-Dotan S, Feldhamer I, Birnbaum Y, Cherny NI. The ESMO-Magnitude of Clinical Benefit Scale for novel oncology drugs: correspondence with three years of reimbursement decisions in Israel [Internet]. Expert Rev Pharmacoecon Outcomes Res. 2018 Feb;18(1):119-22. [cited 2019 Jul 7].

35 Wild C, Grössmann N, Bonanno PV, Bucsics A, Furst J, Garuoliene K, et al. Utilisation of the ESMO-MCBS in practice of HTA [Internet]. Ann Oncol. 2016 Nov;27(11):2134-6. [cited 2019 Jul 7].

36 Institute for Health Informatics. Delivering on the potential of biosimilar medicines. Parsippany: IMS Institute for Health Informatics (2016). Available from: https://www.medicinesforeurope.com/wp-content/uploads/2016/03/IMS-Institute-Biosimilar-Report-Mar. 